\title{
Rumen volatile fatty acid molar proportions, rumen epithelial gene expression, and blood metabolite concentration responses to ruminally degradable starch and fiber supplies
}

\author{
L. Beckett, ${ }^{1} \oplus$ C. B. Gleason, ${ }^{1}{ }^{\oplus}$ A. Bedford, ${ }^{1}{ }^{\oplus}$ D. Liebe, ${ }^{1} \odot$ T. T. Yohe, ${ }^{2} \odot$ M. B. Hall, ${ }^{3} \odot$ K. M. Daniels, ${ }^{2} \odot$ \\ and R. R. White ${ }^{1 *}$ (1) \\ ${ }^{1}$ Department of Animal and Poultry Science, Virginia Tech, Blacksburg 24061 \\ ${ }^{2}$ Department of Dairy Science, Virginia Tech, Blacksburg 24061 \\ ${ }^{3}$ US Dairy Forage Research Center, US Department of Agriculture-Agricultural Research Service, Madison, WI 53706
}

\begin{abstract}
The objective of this work was to characterize rumen volatile fatty acid (VFA) concentrations, rumen epithelial gene expression, and blood metabolite responses to diets with different starch and fiber sources. Six ruminally cannulated yearling Holstein heifers (body weight $=330 \pm 11.3 \mathrm{~kg}$ ) were arranged in a partially replicated Latin square experiment with 4 treatments consisting of different starch [barley (BAR) or corn $(\mathrm{CRN})$ ] and fiber [timothy hay (TH) or beet pulp (BP)] sources. Treatments were arranged as a $2 \times 2$ factorial. Beet pulp and $\mathrm{TH}$ were used to create relative changes in apparent ruminal fiber disappearance, whereas CRN and BAR were used to create relative changes in apparent ruminal starch disappearance. Each period consisted of $3 \mathrm{~d}$ of diet adaptation and $15 \mathrm{~d}$ of dietary treatment. In situ disappearance of fiber and starch were estimated from bags incubated in the rumen from d 10 to 14 . From d 15 to 17, rumen fluid was collected every hour from 0500 to $2300 \mathrm{~h}$. Rumen fluid samples were pooled by animal/period and analyzed for $\mathrm{pH}$ and VFA concentrations. On d 18, 60 to 80 papillae were biopsied from the epithelium and preserved for gene expression analysis. On d 18, one blood sample per heifer was collected from the coccygeal vessel. In situ ruminal starch disappearance rate $(7.30$ to $8.72 \% / \mathrm{h}$ for BAR vs. 7.61 to $10.5 \% / \mathrm{h}$ for $\mathrm{CRN}$ ) and the extent of fiber disappearance (22.2 to $33.4 \%$ of DM for TH vs. 34.4 to $38.7 \%$ of DM for BP) were affected by starch and fiber source, respectively. Analysis of VFA molar proportions showed a shift from propionate to acetate, and valerate to isovalerate on TH diets compared with BP. Corn diets favored propionate over butyrate in comparison
\end{abstract}

Received September 10, 2020.

Accepted March 9, 2021.

*Corresponding author: rrwhite@vt.edu to BAR diets. Corn diets also had higher molar proportions of valerate. Expression of 1 gene (SLC9A3) were increased in $\mathrm{BP}$ diets and 2 genes $(B D H 1$ and $S L C 16 A 4)$ tended to be increased in TH diets. Plasma acetate demonstrated a tendency for a starch by fiber interaction with BAR-BP diets having the highest plasma acetate, but other metabolites measured were not significant. These results suggest that $\mathrm{TH}$ has the greatest effect on shifts in VFA molar proportions and epithelial transporters, but does not demonstrate shifts in blood metabolite concentrations.

Key words: rumen epithelium, blood metabolite, volatile fatty acid dynamics

\section{INTRODUCTION}

Volatile fatty acids are an energy source for ruminants that contribute approximately 70 to $80 \%$ of energy requirements (Bergman, 1990). Ration changes cause adaptations within the rumen microbial community that alter fermentation patterns and contribute to changes in rumen VFA. Dietary ingredients can be used to manipulate VFA because they can alter the type of substrate provided for fermentation (France and Dijkstra, 2005). Although there is considerable information available about how specific starch and fiber sources affect VFA concentrations, Hall et al. (2015) noted that VFA concentrations can be inaccurate representations of treatment effects on fermentation because they do not account for differences among treatments in ruminal liquid volume and passage rate. Liquid passage rate, in particular, has been shown to change with dietary composition and particle size, among other factors (Kuoppala et al., 2009). Although some studies have concurrently evaluated shifts in VFA concentration and fluid passage (e.g., Dijkstra et al., 1993), there has been less focus on how diets with different predicted ruminal carbohydrate disappearance profiles influence VFA and fluid dynamics. 
Rumen liquid volume and passage can be quantified by measuring the exponential decay of a marker concentration (e.g., polyethylene glycol, Cr-EDTA, Co-EDTA) using a time course of rumen fluid samples after dosing (Krämer et al., 2013). Rumen fluid passage is then used to estimate the amount of VFA exiting the rumen with rumen fluid (fluid-mediated flux) and individual VFA pool size. Fluid dynamics also contribute to changing carbohydrate disappearance rates. Krämer et al. (2013) did not see a difference in ruminal retention time due to fiber type or forage ratio but did see changes in total mean retention time, suggesting rumen liquid outflow could alter nutrient retention times in other portions of the gastrointestinal tract. Increased or decreased nutrient retention times could therefore alter VFA profiles and should be considered when evaluating dietary effects on ruminal and postruminal outcomes.

Previous modeling work demonstrated that ruminal starch and fiber disappearances are good predictors of key ruminal factors such as microbial $\mathrm{N}$ production, efficiency of microbial protein synthesis (Roman Garcia et al., 2016), and ruminal pH (White et al., 2017a). Most studies reporting relationships between ruminal VFA and ruminal carbohydrate disappearance focus exclusively on these aspects of fermentation and do not test the downstream responses of the rumen epithelia or blood metabolites. A more holistic analysis of animal responses to ruminal carbohydrate disappearance may help better inform how rations differing in nutrient ruminal disappearances should be formulated to optimize ruminal health and whole-system efficiency.

The objective of this work was to characterize how rumen VFA molar proportions, rumen fluid dynamics, rumen epithelial gene expression, and blood metabolite concentrations respond to diets containing different starch and fiber sources. We hypothesized that corn grain will have a slower rate of starch disappearance than barley grain, thus contributing to more balanced fermentation (moderate $\mathrm{pH}$, lower proportion of propionate). We hypothesized that timothy hay will have lower ruminal fiber disappearance than beet pulp resulting in lower VFA concentrations and higher proportions of acetate. We also expected to detect changes in ruminal VFA transporter gene expression that mirrored VFA molar proportions and shifts in genes associated with epithelial acetate and butyrate metabolism would mirror acetate and butyrate pool sizes. Because blood metabolite concentrations are subject to similar fluid kinetic issues as rumen VFA concentrations (e.g., Hall et al., 2015), blood metabolite concentrations are incomplete representations of metabolite flux (e.g., Bedford et al., 2018). Therefore, we did not expect to detect changes in blood metabolite concentrations that mirror expected shifts in VFA supplies.

\section{MATERIALS AND METHODS}

\section{Animals and Treatments}

All animal use and procedures were in accordance with the guidelines provided by the Virginia Tech Institutional Animal Care and Use Committee. Six ruminally cannulated yearling Holstein heifers (BW: $330 \pm 11.3 \mathrm{~kg}$ ) were used in a partially replicated $4 \times$ 4 Latin square experiment. The square was partially replicated because 6 animals were randomly assigned to 4 treatments, meaning that 2 treatments were duplicated in each period, and the other 2 treatments were not. Treatments were arranged to ensure a different treatment always preceded and followed another treatment. Treatment diets were arranged factorially $(2 \times$ 2 ) and were designed to include feedstuffs expected to result in proportionally different supplies of ruminally degradable starch and fiber but have the same dietary percentage of NDF and starch (Table 1). Ground barley (BAR) and ground corn (CRN) were used as starch sources, with BAR expected to undergo faster ruminal starch degradation because it is known to be the third most degradable starch source behind oats and wheat, respectively (Nikkhah, 2012). Pelleted timothy hay (TH) and pelleted beet pulp (BP), ranging from 1.9 to $2.54 \mathrm{~cm}$ in length and $0.635 \mathrm{~cm}$ in diameter, were used as fiber sources. Timothy hay was expected to have lower rate and extent of ruminal fiber degradability than BP because of the pelleted nature of the timothy hay. Corn silage was the diet base, and a mixture of soybean meal, blood meal, and corn gluten feed were added to meet protein requirements and to ensure the diets were isonitrogenous (Table 1). Diets were not designed to be isoenergetic.

Each animal cycled through the 4 diets over a 4-period time frame. Periods consisted of $18 \mathrm{~d}$. The first 3 d were for gradual diet adaptation to prevent rumen upset. Heifers consumed $100 \%$ of the treatment diet from d 3 to 18 .

\section{Animal Feeding and Sample Collection}

Initially, 8 heifers were to be trained on the Calan gate system (American Calan Inc.) to have a complete replicated Latin square design, but 2 heifers were removed before the start of the acclimation period due to the inability to learn and use the system. The 6 remaining heifers were trained on the Calan gate system gradually over a 2 -wk period before the start of the treatment period. During the acclimation period (Calan gate training period) and treatment period, animals were checked daily at feeding to ensure Calan gate transponders were securely placed. Heifers were 
fed once daily via the Calan gate system at approximately $1000 \mathrm{~h}$ from d 1 to 13 of each period while being housed in a freestall barn. From d 14 to 18, heifers were moved to metabolism stalls and fed every $2 \mathrm{~h}$ starting at $1030 \mathrm{~h}$ in an attempt to achieve metabolic steady state. Diets were hand-weighed per animal and mixed daily before feeding. During 2 -h feeding periods, a full 24-h ration was mixed and evenly divided by weight into 12 aliquots of feed. Amounts of feed offered and refused were weighed daily throughout the experiment including the Calan gate acclimation period. Fresh diet and refusal feed samples were collected on d 6 , 12 , and 18 of each period by animal; feed refusals were collected before each feeding. Samples were dried in a $55^{\circ} \mathrm{C}$ forced-air oven (Thermo Scientific Heratherm Advanced Protocol Ovens Model 51028115, Fisher Scientific) for $48 \mathrm{~h}$ to obtain DM content of each ration. Daily DMI per heifer was calculated by multiplying daily as-fed intake by average DM content of each treatment ration. Body weight was measured at the beginning of the experiment and once between each period (every $18 \mathrm{~d}$ ). In situ degradability of diets was assessed with a 96-h incubation occurring from d 10 to 14 of each period. Further details regarding assessment of in situ degradability will be discussed later. Rumen fluid samples were collected hourly from 0500 to 2300 $\mathrm{h}$ on d 15 through 18 of each period. Blood samples were collected by coccygeal venipuncture at $0900 \mathrm{~h}$ on d 18 of each period. Papillae biopsies were collected immediately following blood sampling as described later.

\section{Feed Analysis}

Dried feed and refusal samples were ground with a Model 4 Wiley mill (A. H. Thomas Scientific) to pass through a 1-mm screen. Ash was determined after heating ground feed samples for $8 \mathrm{~h}$ in a muffle furnace $\left(500^{\circ} \mathrm{C}\right)$. An Ankom200 fiber analyzer (Ankom Technology) with the addition of neutral detergent, heat-stable $\alpha$-amylase, and sodium sulfite was used to determine NDF of feed samples using Ankom fiber filter bags (pore size $=25 \mu \mathrm{m}$; Van Soest, et al., 1991). Feed ADF content was assessed using the Ankom200 fiber analyzer and the same Ankom fiber filter bags previously described (Ankom Technology; Van Soest et al., 1991). Both NDF and ADF analysis included ash in the sample. Crude protein was calculated as $\mathrm{N} \times 6.25$ after quantification of total $\mathrm{N}$ by combustion analysis (Vario El Cube CN analyzer, Elementar Americas Inc.). Starch concentrations were determined using the acetate buffer method of Hall (2009) with $\alpha$-amylase from Bacillus licheniformis (FAA, Ankom Technology) and amyloglucosidase from Aspergillus niger (E-AMGDF, Megazyme International).

\section{In Situ Degradability}

Diets were prepared according to the formulations in Table 1, dried in a forced-air oven for $48 \mathrm{~h}$ at $55^{\circ} \mathrm{C}$, and ground through a $2-\mathrm{mm}$ screen of a Wiley mill (Thomas Scientific). A total of 40 Dacron bags per heifer (An-

Table 1. Diet ingredient and nutrient inclusion for each treatment diet that were designed to provide different sources of ruminal starch and fiber to yearling Holstein heifers

\begin{tabular}{lcccc}
\hline & \multicolumn{3}{c}{ Diet $^{1}$} \\
\cline { 2 - 4 } Item & BAR-TH & BAR-BP & CRN-TH & CRN-BP \\
\hline Ingredient, \% of DM & & & & \\
Timothy hay & 19.9 & 0.02 & 25.0 & 1.43 \\
Beet pulp & 6.05 & 30.2 & 3.55 & 32.9 \\
Ground corn & 0.38 & 0.00 & 10.5 & 12.3 \\
Ground barley & 14.1 & 14.8 & 0.67 & 0.31 \\
Corn silage & 34.4 & 35.6 & 35.2 & 29.4 \\
Corn gluten feed & 3.26 & 0.00 & 1.65 & 7.22 \\
Soybean meal & 9.30 & 17.1 & 9.95 & 15.3 \\
Blood meal & 3.78 & 0.00 & 4.37 & 0.04 \\
Nutrient, ${ }^{2} \%$ of DM & & & & 74.7 \\
DM & 64.8 & 73.4 & 63.9 & 35.0 \\
NDF & 35.0 & 35.0 & 35.0 & 20.0 \\
Starch & 20.0 & 20.0 & 20.0 & 16.0 \\
CP & 15.9 & 16.0 & 15.9 & 2.75 \\
Estimated ME, Mcal/kg & 2.63 & 2.74 & 2.62 & \\
\hline
\end{tabular}

${ }^{1} \mathrm{BAR}-\mathrm{TH}=$ ground barley and timothy hay pellets. BAR-BP $=$ ground barley and beet pulp pellets. CRN-TH $=$ ground corn and timothy hay pellets. CRN-BP $=$ ground corn and beet pulp pellets.

${ }^{2}$ Diets were formulated to have similar nutrient inclusion (\% of DM), but were not formulated to be isoenergetic. 
kom R1020, $10 \times 20 \mathrm{~cm}$ and $50 \pm 10 \mu \mathrm{m}$ porosity, Ankom Technology) were filled with $5 \mathrm{~g}$ of ground diet samples (DM basis) and heat-sealed. An empty bag was also included for each diet to serve as a blank. In situ bags were placed in mesh laundry bags (20 Dacron bags per mesh bag) and incubated in the rumen at: $-96,-48,-24,-12,-6,-3,-1.5,-1,-0.5$, and $0 \mathrm{~h}$. Heifers were only incubated with the diet they were fed during that period. At time 0, all bags were removed and washed 5 times with a portable washing machine (SKY2767, Best Choice Products). Each wash cycle consisted of $1 \mathrm{~min}$ of cool water agitation, drainage, and a 2-min spin. After washing, bags were dried in a forced-air oven for $48 \mathrm{~h}$ at $55^{\circ} \mathrm{C}$. Bags were immediately weighed postdrying and weighed again after 3 $\mathrm{h}$ of air equilibration. Bag contents were then pooled by animal/time point and subjected to the previously described NDF and starch analyses.

Residual amount of each nutrient (NDF and starch) was calculated as the nutrient percentage in each bag multiplied by the DM content in each bag to yield residual grams of nutrient. An exponential decay curve was fitted to the calculated nutrient disappearance (\% of total disappeared). The slope of this exponential function was multiplied by 100 to yield the fractional nutrient disappearance rate $(\% / \mathrm{h})$. A maximal extent of disappearance was calculated as the nutrient concentration at $0 \mathrm{~h}$ minus the nutrient concentration at $96 \mathrm{~h}$ divided by the nutrient concentration at time $0 \mathrm{~h}$, multiplied by $100 \%$.

\section{Rumen Fluid Volume, Passage Rate, and VFA Concentrations}

A 250-mL polyethylene glycol (PEG; average MW 8000; FisherScientific) intraruminal bolus (38.5 g PEG $/ 250 \mathrm{~mL}$ of water) was administered at $0500 \mathrm{~h}$ on $\mathrm{d} 15$. The bolus was administered by funneling solution directly into the rumen through the cannula. Ruminal contents were mixed by hand for $1 \mathrm{~min}$ after the bolus was delivered. Immediately before administration of this bolus, 2 initial $(0 \mathrm{~h})$ rumen fluid samples (12 $\mathrm{mL} /$ sample) were collected. An additional $0 \mathrm{~h}$ sample $(12 \mathrm{~mL})$ was collected immediately following the bolus, despite recognizing that markers do not equilibrate in rumen fluid until $\sim 2 \mathrm{~h}$ after dosing (Owens and Hanson, 1992). Rumen fluid samples (12 mL) were then collected hourly until $2300 \mathrm{~h}$. Sampling on d 16 and 17 also occurred hourly between 0500 and $2300 \mathrm{~h}$, as described above. Rumen fluid samples $(12 \mathrm{~mL})$ were collected via polyethylene sampling lines terminating in weighted pot scrubbers, threaded through holes drilled in the rumen cannula cap, and attached to $60 \mathrm{~mL}$ syringes. Samples $(12 \mathrm{~mL})$ were taken from 2 locations within the ventral lateral portion of the rumen, pooled in the sampling syringe, and split equally into three 5 -mL glass vials for storage at $-20^{\circ} \mathrm{C}$.

Samples from 0500 to $1700 \mathrm{~h}$ of d 15 were analyzed for concentrations of PEG using a protocol modification (M. B. Hall, unpublished protocol) of Smith (1959) with samples handled by centrifugation and careful volumetric additions of reagents rather than by filtration and use of volumetric flasks. Rumen fluid PEG concentrations were fitted to an exponential decay curve over time. The slope of this curve was used to calculate the fractional fluid passage rate $(\% / \mathrm{h} ; 100 \times$ slope). The quantity of PEG dosed to each animal was divided by the $0 \mathrm{~h}$ postdosing intercept of the curve to yield an estimate of fluid volume. Fluid volume is more appropriately measured by other techniques (e.g., bailing the rumen) but these approaches were not used in this study because microbial RNA samples were also collected (data not presented here), and there was concern that repeated bailing of the rumen would disrupt microbial populations and functionality.

At 0700 and $1900 \mathrm{~h}$, rumen fluid $(4 \mathrm{~mL})$ was spot sampled for $\mathrm{pH}$ before storage. No diurnal patterns were observed in raw rumen $\mathrm{pH}$ data obtained from spot sampling and therefore rumen $\mathrm{pH}$ data were averaged within day ( $3 \mathrm{~d}$ of measurements per period). All $\mathrm{pH}$ measurements were collected on-farm within $1 \mathrm{~min}$ of sample collection using a calibrated benchtop $\mathrm{pH}$ meter (Fisherbrand Accumet AE150, Fisher Scientific).

Rumen fluid samples were also used to measure rumen VFA concentrations by gas chromatography (Firkins et al., 1990). A total of $500 \mu \mathrm{L}$ from each hourly sample obtained within an animal-period was composited to create 1 sample/animal per period that was used for analysis. The rumen VFA pool sizes were estimated as the VFA concentration $(\mathrm{m} M)$ multiplied by the rumen fluid pool size (L). Fluid-mediated flux of VFA $(\mathrm{mmol} / \mathrm{h})$ from the rumen was estimated as the rumen VFA pool size $(\mathrm{mmol} / \mathrm{L})$ multiplied by the fluid passage rate $(\% / \mathrm{h})$, and divided by the rumen fluid pool size (L). It was assumed that VFA production is equated to VFA exit from the rumen and rumen fluid volume is constant over time. It is acknowledged that VFA removal from the rumen is a function of both rumen fluid passage and rumen epithelial absorption, which will be discussed later.

\section{Blood Metabolite Sample Collection and Analysis}

Blood samples were collected from the coccygeal vessel at $0900 \mathrm{~h}$ on d 18 of each period into $10 \mathrm{~mL}$ sodium heparin vacutainer vials (Becton Dickinson). Samples were kept on ice until plasma isolation. Plasma was isolated by centrifuging blood tubes at $1,500 \times g$ for 10 
min at $-4^{\circ} \mathrm{C}$. Samples were stored at $-20^{\circ} \mathrm{C}$ until VFA derivatization and $\mathrm{BHB}$, glucose, and insulin analysis. Plasma acetate and propionate concentrations were derivatized following Kristensen's (2000) method for GC-MS analysis. In short, plasma was combined with acetonitrile and 2-chloroethanol before centrifuging at $1,500 \times g$ for $30 \mathrm{~min}$ at $-4^{\circ} \mathrm{C}$. After centrifuging, the supernatant, $\mathrm{NaOH}$, and heptane were combined to allow phase separation. The bottom phase was removed and transferred to a new vial for the addition of $\mathrm{HCl}$, pyridine, chloroethyl chloroformate, and water. Lastly, chloroform was added to complete derivatization. Samples $(0.80 \mu \mathrm{L})$ were analyzed on a Thermo Electron Focus gas chromatograph (Thermo Scientific) working with a Thermo Electron Polaris Q mass spectrometer (Thermo Scientific) and XCalibur software (version 1.4; Thermo Scientific). Plasma BHB concentrations were measured using a BHB (ketone body) colorimetric assay kit (Cayman Chemical Item No. 700190, Cayman Chemical). Plasma glucose concentrations were measured using Stanbio Glucose Liquid Reagent for Diagnostic Set (Fisher Scientific SB-1070-125). Plasma insulin concentrations were measured using a chemiluminescence assay (Siemens Immulite 2000 XPi Immunoassay System).

\section{Papillae Biopsy Sample Collection and Analysis}

Rumen papillae samples were collected on d 18 immediately following blood collection. During papillae biopsies, heifers were restrained in a head gate and working chute. Biopsies were collected by cutting 60 to 80 papillae from the ventral surface of the epithelium using cuticle scissors. The rumen was not emptied before sampling. To access rumen papillae, an assistant firmly grasped the ventral sac of the rumen and inverted the epithelium through the cannula, exposing it for sampling. Before removal, papillae were rinsed with phosphate buffered saline (potassium phosphate monobasic $210 \mathrm{mg} / \mathrm{L}$; sodium chloride $9,000 \mathrm{mg} / \mathrm{L}$; sodium phosphate dibasic, $726 \mathrm{mg} / \mathrm{L}$, Gibco Life Technologies, $\mathrm{pH}$ 7.0) from a squeeze bottle. Upon excision, papillae were immediately immersed in an RNA preservative solution (RNALater; Qiagen). Papillae and RNA preservative were transferred into cryovials and stored at $-80^{\circ} \mathrm{C}$ until total RNA isolation. Total RNA was extracted using the Qiagen RNeasy Mini Kit (Qiagen). Briefly, approximately $30 \mathrm{mg}$ of rumen papillae were removed from storage and placed into $600 \mu \mathrm{L}$ of lysis buffer $(10 \mu \mathrm{L}$ of $\beta$-mercaptoethanol in every $1 \mathrm{~mL}$ of buffer RLT). Tissue was disrupted via homogenization at top speed for $30 \mathrm{~s}$ and the homogenate was placed on ice until centrifugation. After centrifugation at $>20,000$ $\times g$ for $3 \mathrm{~min}$ at $23^{\circ} \mathrm{C}$, supernatant was removed and combined with one volume of $70 \%$ ethanol. Up to 700 $\mu \mathrm{L}$ of sample from each original tissue preparation were transferred to a new RNeasy Mini spin column placed in a 2-mL collection tube. Tubes and column inserts were centrifuged for $15 \mathrm{~s}$ at $>8,000 \times g$ at $23^{\circ} \mathrm{C}$. The flow-through was discarded. The DNase was not used. Next, $700 \mu \mathrm{L}$ of buffer RW1 were added to each spin column; samples were centrifuged for $15 \mathrm{~s}$ at $>8,000 \times$ $g$ at $23^{\circ} \mathrm{C}$; the flow-through was discarded. Then, 500 $\mu \mathrm{L}$ of buffer RPE were added to each spin column; samples were centrifuged for $15 \mathrm{~s}$ at $>8,000 \times g$ at $23^{\circ} \mathrm{C}$; the flow-through was discarded. Then, $500 \mu \mathrm{L}$ of buffer RPE were added to each spin column; samples were centrifuged for $2 \mathrm{~min}$ at $>8,000 \times g$ at $23^{\circ} \mathrm{C}$; the flow-through was discarded. To elute total RNA, each spin column was placed in a new collection tube and $30 \mu \mathrm{L}$ of nuclease-free water were added to each spin column membrane; samples were centrifuged for $1 \mathrm{~min}$ at $>8,000 \times g$ at $23^{\circ} \mathrm{C}$. Total RNA quantity was determined using $2 \mu \mathrm{L}$ of sample deposited on a $\mu$ Drop Plate and read on a spectrophotometer (ThermoFisher Scientific). Total RNA quality was assessed using a spectrophotometer and evaluated by the 260:280 ratio of $\geq 2 \pm 0.10$. Samples outside of the range were re-read another time and removed from further analysis if not within the previously described range. Three samples were removed from further analysis based on these parameters. Single-stranded cDNA was synthesized from each RNA sample using the Applied Biosystems HighCapacity cDNA reverse transcription kit (catalog \# 4368814; ThermoFisher Scientific) and a thermocycler.

Fourteen genes were chosen for analysis because of their roles in rumen epithelial transport, epithelial integrity, or VFA metabolism. Genes of interest included: monocarboxylate transporters 1,2 , and 4 (SLC16A1, SLC16A7, SLC16A4), sodium hydrogen exchanger isoforms 1, 2, and 3 (SLC9A1, SLC9A2, SLC9A3), claudin-1 (CLDN1), gap junction protein a 1 (GJA1), acetoacetyl-CoA synthetase $(A A C S)$, 3-hydroxybutyrate dehydrogenase type 1 (BDH1), 3-hydroxymethyl3-methylglutaryl-CoA lyase (HMGCL), 3-hydroxy3-methylglutaryl-CoA synthase 2 (HMGCS2), and serine-threonine protein kinase $(A K T 1)$. Several endogenous control genes were considered; of these, ribosomal protein S15 (RPS15) was the most stable across samples and was therefore selected as the sole endogenous control gene. Primers were designed with Primer3 (v. 0.4.0; http://bioinfo.ut.ee/primer3-0.4.0/; Rozen and Skaletsky, 2000). Validation of primers consisted of melting curve analyses performed after each assay to determine whether primer dimers or genomic DNA contamination were present during the assay. Primer information is presented in Supplemental Table S1 (https://github .com/lbecket/rumenresponsestodegradablenutrients). 
Each real-time reverse-transcription quantitative PCR assay was performed on all samples in triplicate, with each reaction mixture $(10 \mu \mathrm{L})$ containing: $0.5 \mu \mathrm{L}$ each forward and reverse primer, $5 \mu \mathrm{L}$ of SYBR Fast Green Master Mix (Fisher 43-856-12, Fisher Scientific), $3 \mu \mathrm{L}$ of RNase-DNase-free water, and $1 \mu \mathrm{L}$ of cDNA (1:1 stock). Assays were performed using an Applied Biosystems 7500 Real-Time PCR system (ThermoFisher Scientific). Cycling conditions were as reported by $\mathrm{Lu}$ et al. (2017). Each assay included a no-template control and a no-reverse-transcriptase control, with the no-template control receiving $1 \mu \mathrm{L}$ of RNase-DNase-free water instead of cDNA, whereas the no-reverse-transcriptase control received a $1-\mu \mathrm{L}$ sample of the reverse transcription product to which no reverse transcriptase was added.

Efficiency of each run was calculated and evaluated. Target genes of interest were normalized to the mean of RPS15 in the following manner: target gene cycle threshold $(\mathbf{C t})$ - reference gene $\mathrm{Ct}=\Delta \mathrm{Ct}$. Relative mRNA abundance expressed as $2^{-\Delta \mathrm{Ct}}$ values and higher values equated to more mRNA.

\section{Calculations and Statistical Analysis}

All statistical analyses were conducted using the nlme package of $\mathrm{R}$ version 3.1.0. (https://ww.r-project .org). Dry matter intake (kg/d), ADG (kg/d), VFA concentrations $(\mathrm{m} M)$, VFA molar proportions $(\%$ of total VFA), fluid volume (L), fluid passage rate $(\% / \mathrm{h})$, calculated VFA pool sizes (mmol), calculated VFA fluid exit rates (mmol), epithelial gene expression as $2^{-\Delta \mathrm{Ct}}$ values, and blood metabolite concentrations ( $\mathrm{m} M, \mathrm{mg} /$ $\mathrm{dL}$, or $\mu \mathrm{IU} / \mathrm{mL}$ ) were considered as response variables. The following linear mixed effect model was used for analysis of all response variables:

$$
Y_{i j k l}=\mu+\alpha_{i}+\beta_{j}+\alpha \beta_{i j}+c_{k}+d_{1}+e_{i j k l},
$$

where $\mu$ is the overall mean, $\alpha_{i}$ is the effect of the $i$ th starch source, $\beta_{j}$ is the effect of the $j$ th fiber source, $\alpha \beta_{i j}$ is the interaction of starch source $i$ and fiber source $j, c_{k}$ is the random effect of animal $k, d_{l}$ is the random effect of period $l$, and $e_{i j k l}$ is the residual error associated with starch source $i$, fiber source $j$, animal $k$, and period $l$.

For each response variable, different residual error variance structures (unstructured, compound symmetry, and first-order autoregressive) were compared and the model with the lowest Akaike information criterion (first-order autoregressive in all cases) was used to test significance. ANOVA and least squares means were computed for each model. Despite a prevailing lack of significant interactions, least squares means for each treatment combination are presented to enable future model-based work, which may benefit from these treatment-specific values. Treatment effects were considered significant at $P<0.05$, a tendency at $P<0.10$ for main effects, and a tendency at $0.05<P<0.15$ for an interaction.

\section{RESULTS AND DISCUSSION}

\section{Dry Matter Intake}

Average DMI for all treatments throughout all periods is shown in Table 2. Dry matter intake was affected by fiber source $(P=0.009)$ but was unaffected by starch source $(P=0.29)$ or the interaction between fiber and starch sources $(P=0.46)$. Heifers fed BP diets consumed less than heifers on TH diets. There are several reasons why DMI may have differed among treatments. It is possible that heifers found $\mathrm{BP}$ to be less palatable than TH. We believe palatability may have been an issue because the BP had to be soaked in water before ration mixing to entice animals to consume it. Alternatively, it is possible that the higher expected energy concentration of BP diets (estimated ME, Mcal/kg 2.74 and 2.75; Table 1) caused lower DMI. Allen (2000) discussed highly fermentable starch diets decreased DMI most likely due to increased propionate production providing satiety feedback to the brain (Allen et al., 2009). Discussed later in detail, the BP diets tended to have increased molar proportions of propionate (Table 3), which may support hepatic oxidation and subsequent activation of satiety feedback mechanisms in the brain (Allen et al., 2009). However, starch source also significantly affected molar proportions of propionate and did not significantly influence DMI, suggesting additional mechanisms are responsible for influencing DMI on these diets. Additionally, it is possible that the lack of starch source effect on DMI was because the extent of starch disappearance did not differ among diets, only the rate of starch disappearance.

\section{Nutrient Degradability}

Starch and fiber rate and extent of disappearance results for each diet are shown in Table 2. Starch source affected the rate of starch disappearance $(P=0.05)$ but not the extent of disappearance by $96 \mathrm{~h}(P=0.25)$. There was a tendency for an interaction on extent of starch disappearance rate $(P=0.12)$. Timothy hay tended to affect starch disappearance rate by $96 \mathrm{~h}(P$ $=0.09$ ), but did not affect extent of disappearance $(P=0.42)$. These results were expected because the 


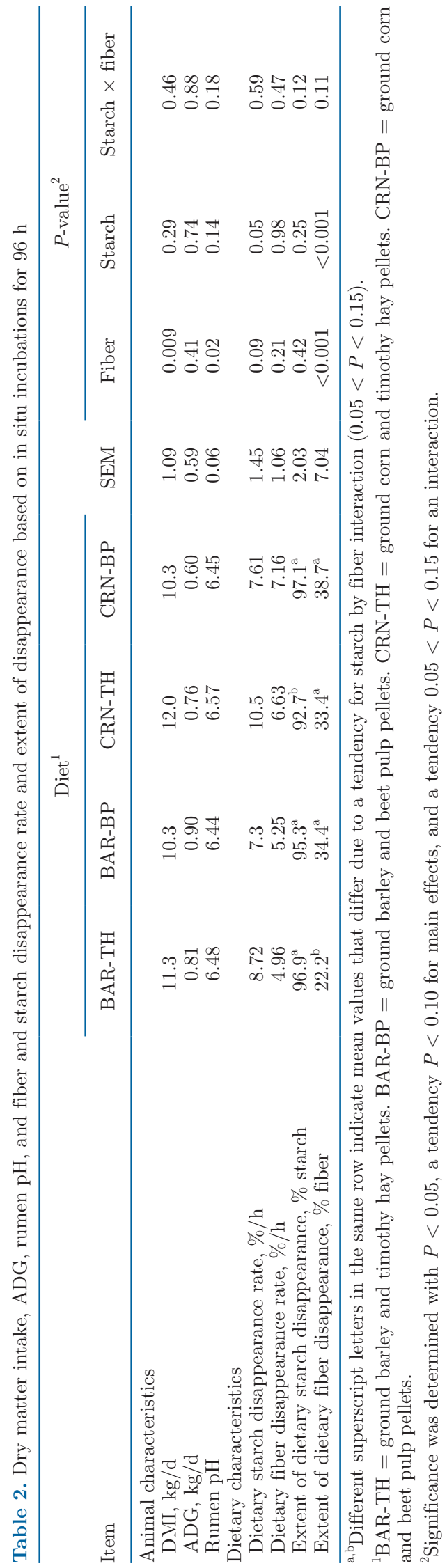

rumen is the primary location for starch degradation, regardless of the ingredient being described as highly or lowly degradable in the rumen. Starch from barley and corn has been thought to have differing ruminal extents of disappearance using in situ ruminal disappearance as a method over a 48-h period and the same starch analytical method described in the present study (Ferreira et al., 2018). The lack of statistical difference in extent of disappearance could be explained by the nearly $100 \%$ disappearance of starch from both sources by $96 \mathrm{~h}$, which could be a function of grinding methods accompanied with ruminal incubation time, similar proline content of the endosperm (Kung et al., 2014) or lack of variation in endosperm vitreousness between these sources of cereal grain (Ferreira et al., 2018).

Starch in CRN diets disappeared faster (7.61 to $10.5 \% / \mathrm{h}$ ) than in BAR diets (7.30 to $8.52 \% / \mathrm{h}$; Table 2 ), which was not expected despite both ground corn and ground barley having observationally similar particle sizes (not confirmed with a Penn State shaker box or other particle-size sieves). The difference in starch disappearance rate contradicts Ferreira et al. (2018), who used in situ ruminal disappearance as a method over a 48-h period and the same starch method described in the present study. Ferreira et al. (2018) showed corn grain to have a slower disappearance rate than hulled barley. However, it is possible the additional $48 \mathrm{~h}$ in the rumen during the present study aided in further disappearance of the corn. The corn fed to heifers was not pelleted and did not go through any high-heat processing. It is possible that this lack of processing contributed to faster degradation. The differences between these studies may be due to testing dietary starch disappearance versus testing individual ingredient starch disappearance. Additional work is needed to explain why corn-based diets in the present study had faster starch disappearance rates than corresponding barley diets.

Calculated fiber disappearance rate was not influenced by starch source $(P=0.98)$, fiber source $(P=$ $0.21)$, or the interaction of starch and fiber sources $(P$ $=0.47)$. Extent of fiber disappearance was affected by fiber source $(P<0.001$; Table 2$)$ and starch source $(P$ $<0.001$; Table 2). The interaction of starch and fiber sources tended to $(P=0.11)$ influence extent of fiber disappearance. Beet pulp diets had a higher extent of fiber disappearance than $\mathrm{TH}$ diets. This was expected because BP is a more rapidly degradable fiber source compared with other by-product feedstuffs (DePeters et al., 1997; Fadel et al., 2000), and TH is known to have a thicker, denser cell wall than BP (Van Soest et al., 1991). Varga and Hoover (1983) reported different extents of degradation for BP (68.9\% total NDF) and timothy $(47.1 \%$ total $\mathrm{NDF})$, which are similar to the values in the present study. 


\section{Rumen $\mathrm{pH}$}

Rumen $\mathrm{pH}$ was affected by fiber source ( $\operatorname{starch} P=$ 0.14 ; fiber $P=0.02$; starch $\times$ fiber $P=0.18$; Table 2 ). Timothy hay diets caused higher ruminal $\mathrm{pH}$ in comparison to BP diets. This result was expected because the role of forage NDF in maintaining rumen health has been well-characterized (White et al., 2017a,b) despite the TH in the present study being pelleted. The more soluble fiber present in BP is not expected to have the same buffering potential as forage NDF (Firkins, 1997). There was no significant starch effect on rumen $\mathrm{pH}$. By feeding every $2 \mathrm{~h}$, diurnal $\mathrm{pH}$ fluctuations associated with different rates of starch disappearance could have been minimized.

\section{Volatile Fatty Acid Molar Proportions and Concentrations}

Treatment means and $P$-values for rumen VFA molar proportions are shown in Table 3. Total VFA concentration is reported in Table 3 for coherence with the previous literature only. Hall et al. (2015) demonstrated that concentrations are unreliable representations of treatment effects because they fail to account for fluid pool size, absorption, and passage rate. As such, only molar proportions, calculated total VFA pool size, and fluidmediated fluxes are discussed. Isovalerate $(\% \mathrm{~mol})$ was the only rumen VFA to be influenced by a starch by fiber interaction $(P=0.05)$. Heifers consuming the $\mathrm{TH}$ diets had the highest molar proportion of isovalerate (Fiber $P=0.01$ ) in comparison to BP. Catabolism of amino acids is a primary source of branched chain VFA production (El-Shazly, 1952), but their net amount in the rumen will also be influenced by microbial utili- zation of amino and fatty acids (Allison and Bryant, 1963; Allison et al., 1962). The inconsistent averages of isovalerate molar percentage could be explained by changes in the molar proportions of other VFA, varying degrees of isovalerate use by ruminal microbes, or varying ruminal protein degradability among diets (CRN vs. BAR, TH vs. BP) even though diets were formulated to be isonitrogenous. Molar proportions of ruminal acetate $(P=0.02)$ was greater when animals were fed TH diets in comparison to BP diets. Ruminal propionate $(P=0.06)$ and valerate $(P=0.10)$ molar proportions also tended to increase when animals were fed BP diets compared with TH diets. This shift in VFA molar proportions from an acetate-based fermentation toward increased proportions of propionate and valerate is likely due to the increased ruminal degradability of NDF of the BP diets (Sutton et al., 2003; Naderi et al., 2016). Ruminal propionate $(P=0.02)$ and valerate $(P=0.05)$ molar proportions were decreased on BAR diets, but butyrate molar proportion increased $(P$ $=0.04)$ in comparison to CRN diet counterparts. The shift from propionate and valerate to increased butyrate may have been due to the slower apparent starch degradation rate of barley- versus corn-based diets (Deckardt et al., 2013), which is contrary to Chibisa et al. (2015) ruminal VFA and rumen $\mathrm{pH}$ results.

\section{Rumen Fluid Volume}

Estimated rumen fluid pool size (rumen fluid volume) and rumen fluid passage rate are shown in Table 4. Estimated rumen fluid volume (L) was unaffected by treatment (starch $P=0.32$; fiber $P=0.89$; starch $\times$ fiber $P=0.54)$, but estimated rate of passage $(\% / \mathrm{h})$ demonstrated a significant fiber effect with $\mathrm{TH}$ diets

Table 3. Calculated VFA molar proportions (\% mol) presented as LSM for yearling Holstein heifers receiving diets differing in expected starch and fiber ruminal disappearance

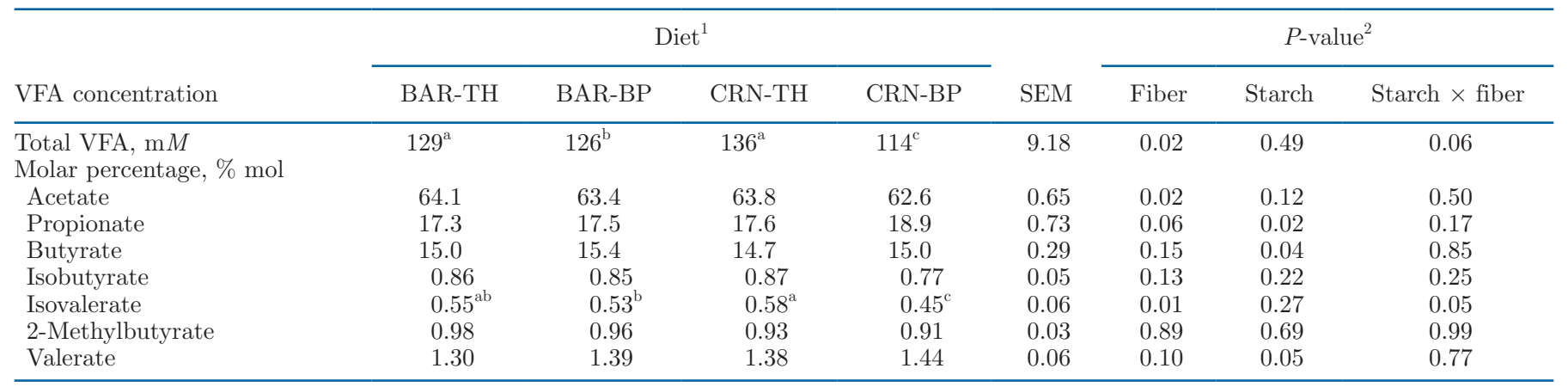

${ }^{\mathrm{a}-\mathrm{c}}$ Different superscript letters in the same row indicate mean values that differ due to a tendency for a starch by fiber interaction $(0.05<P<$ $0.15)$.

${ }^{1} \mathrm{BAR}-\mathrm{TH}=$ ground barley and timothy hay pellets. BAR-BP $=$ ground barley and beet pulp pellets. CRN-TH $=$ ground corn and timothy hay pellets. $\mathrm{CRN}-\mathrm{BP}=$ ground corn and beet pulp pellets.

${ }^{2}$ Significance was determined with $P<0.05$, a tendency $P<0.10$ for main effects, and a tendency $0.05<P<0.15$ for an interaction. 
having a fluid passage rate of $13.1 \% / \mathrm{h}$ compared with $\mathrm{BP}$ at $5.76 \% / \mathrm{h}$ (starch $P=0.27$; fiber $P<0.001$; starch $\times$ fiber $P=0.38)$. A potential explanation to the differences demonstrated could be due to not measuring PEG concentration present in a digesta sample. It is possible for PEG to be present in the fiber fraction due to not evacuating the rumen before blousing, thus, potentially underestimating the PEG concentration. Given that $\mathrm{BP}$ diets had to be prehydrated before consumption, there could be a possibility that ruminal hydration of the TH could dilute the PEG concentration. However, this is unlikely because TH diets had lower DM in comparison to BP diets. Fluid volume and passage rate are dependent upon water intake and osmolality. Water intake can be influenced by DMI (Little and Shaw, 1978); and the significant fiber effect on DMI observed in this study could translate to significant differences in fluid volume or passage rate. Osmolality of rumen fluid was not measured in this study, but it is possible that shifts in osmolality offset any potential shifts in water intake associated with varying DMI among diets. Conversely, potential differences in water intake and osmolality among diets may have been sufficient to drive changes in fluid volume and passage rate. Due to the differences in rumen fluid passage among diets, we believe the latter is more likely.

Estimated total rumen fluid passage $(\mathrm{L} / \mathrm{h})$ was calculated by multiplying estimated rumen fluid volume by estimated rate of passage $(\% / \mathrm{h})$. Estimated rate of passage $(\mathrm{L} / \mathrm{h})$ was also unaffected by treatment (starch $P=0.31$; fiber $P=0.52$; starch $\times$ fiber $P=0.23$; not shown). Although not significant, the fluid passage $(\mathrm{L} / \mathrm{h})$ data followed a similar pattern to the extent of fiber degradation data suggesting a possible relationship between the extent of fiber degradation and the fluid movement from the rumen.

\section{Individual VFA Pool Size and Calculated Fluid-Mediated Flux}

Individual VFA pool size and calculated fluid-mediated flux are shown in Table 4. None of the estimated VFA pool sizes were affected by diet $(P>0.15)$. This lack of significance further highlights the need to evaluate fermentation in the context of fluid dynamics. If we had evaluated differences based on concentration or molar proportion alone, the results may have suggested greater differences among diets than are implied based on this pool-size analysis.

Corresponding to the significant effect of fluid passage rate given the assumptions made, $\mathrm{TH}$ diets significantly increased all VFA passage from the rumen with the fluid fraction $(P<0.001)$. There was not a significant effect of starch source $(P>0.15)$. Interpreting the biological significance of fluid-mediated VFA flux from the rumen is difficult because most of this VFA is likely

Table 4. Rumen fluid characteristics, fluid-mediated VFA flux, and ruminal VFA pool size, as well as significance values for fiber and starch effects and their interaction for yearling Holstein heifers receiving diets differing in expected starch and fiber ruminal disappearance

\begin{tabular}{|c|c|c|c|c|c|c|c|c|}
\hline \multirow[b]{2}{*}{ Item } & \multicolumn{4}{|c|}{ Diet $^{1}$} & \multirow[b]{2}{*}{ SEM } & \multicolumn{3}{|c|}{$P$-value ${ }^{2}$} \\
\hline & BAR-TH & BAR-BP & CRN-TH & CRN-BP & & Fiber & Starch & Starch $\times$ fiber \\
\hline \multicolumn{9}{|l|}{ Rumen fluid } \\
\hline Fluid pool size, L & 50.1 & 43.6 & 36.0 & 40.2 & 8.18 & 0.89 & 0.32 & 0.54 \\
\hline Fluid passage rate, $\% / \mathrm{h}$ & 13.0 & 4.71 & 13.2 & 6.80 & 1.57 & $<0.001$ & 0.27 & 0.38 \\
\hline \multicolumn{9}{|c|}{ Fluid-mediated VFA flux, ${ }^{3} \mathrm{mmol} / \mathrm{h}$} \\
\hline Acetate & 11.1 & 3.77 & 11.1 & 4.70 & 1.47 & $<0.001$ & 0.64 & 0.62 \\
\hline Propionate & 2.92 & 1.05 & 3.13 & 1.44 & 0.43 & $<0.001$ & 0.25 & 0.72 \\
\hline Butyrate & 2.55 & 0.94 & 2.53 & 1.08 & 0.34 & $<0.001$ & 0.81 & 0.75 \\
\hline Valerate & 0.220 & 0.080 & 0.250 & 0.098 & 0.032 & $<0.001$ & 0.38 & 0.92 \\
\hline Isobutyrate & 0.151 & 0.048 & 0.158 & 0.056 & 0.021 & $<0.001$ & 0.64 & 0.96 \\
\hline Isovalerate & 0.098 & 0.029 & 0.107 & 0.032 & 0.016 & $<0.001$ & 0.69 & 0.83 \\
\hline 2-Methylbutyrate & 0.162 & 0.055 & 0.166 & 0.059 & 0.030 & $<0.001$ & 0.90 & 0.99 \\
\hline \multicolumn{9}{|l|}{ VFA pool size, ${ }^{4} \mathrm{mmol} / \mathrm{L}$} \\
\hline Acetate & 4,215 & 3,443 & 3,026 & 2,870 & 789 & 0.54 & 0.24 & 0.68 \\
\hline Propionate & 1,109 & 939 & 903 & 875 & 233 & 0.65 & 0.53 & 0.74 \\
\hline Butyrate & 978 & 964 & 740 & 705 & 218 & 0.72 & 0.34 & 0.85 \\
\hline Valerate & 84.9 & 73.5 & 76.3 & 66.6 & 21.2 & 0.58 & 0.68 & 0.96 \\
\hline Isobutyrate & 55.7 & 45.8 & 45.1 & 32.6 & 11.6 & 0.32 & 0.29 & 0.91 \\
\hline Isovalerate & 36.2 & 28.3 & 30.8 & 18.7 & 7.86 & 0.19 & 0.32 & 0.78 \\
\hline 2-Methylbutyrate & 59.9 & 54.3 & 59.5 & 45.6 & 21.2 & 0.63 & 0.82 & 0.84 \\
\hline
\end{tabular}

${ }^{1} \mathrm{BAR}-\mathrm{TH}=$ ground barley and timothy hay pellets. BAR-BP $=$ ground barley and beet pulp pellets. CRN-TH $=$ ground corn and timothy hay pellets. CRN-BP = ground corn and beet pulp pellets.

${ }^{2}$ Significance was determined with $P<0.05$, a tendency $P<0.10$ for main effects, and a tendency $0.05<P<0.15$ for an interaction.

${ }^{3}$ VFA flux $(\mathrm{mmol} / \mathrm{h})=$ VFA escaping the rumen with fluid passage.

${ }^{4} \mathrm{VFA}$ pool size $(\mathrm{mmol})=$ amount present as a function of rumen liquid volume. 
absorbed in the omasum (Rupp et al., 1994). Thus, the difference from VFA absorbed directly from the rumen is likely minimal. Future work quantifying postruminal VFA absorption may help clarify the biological importance of this flux. Although VFA pool size gives a better understanding of potential VFA available to the animal, measured fluxes of VFA available from isotope studies are needed to fully characterize absorption, interconversion, and other biologically-relevant fluxes.

\section{Gene Expression}

Gene expression data expressed as $2^{-\Delta \mathrm{Ct}}$ is shown in Table 5. The TH diet tended to promote expression of the $B D H 1$ gene $(P=0.08)$. Butyrate availability likely drives metabolism of butyrate in the rumen epithelium, resulting in increased expression of genes involved in that metabolic pathway. The genes investigated in the present study involved in butyrate metabolism were not differentially expressed on TH diets, however. This inconsistency may reflect insufficient variation among responses to reliably detect differences between treatments or could indicate that $B D H 1$ is more rate limiting than other steps in this pathway.

Sodium hydrogen exchanger isoform 3 expression was higher in $\mathrm{BP}$ diets than TH diets $(P=0.05)$. The suggested role of $S L C 9 A 3$ in the rumen is to help maintain epithelial homeostasis by transporting sodium into the cell and transporting protons into the rumen (Connor et al., 2010). Interestingly, BP diets demonstrated a lower $\mathrm{pH}$ than $\mathrm{TH}$ diets suggesting greater protons are in the rumen of animals that consumed BP diets, which appears to correlate with the apparent role of $S L C 9 A 3$. The activation of this gene may reflect increased pressure to maintain both ruminal and epithelial homeostasis on diets that result in differing rumen $\mathrm{pH}$, as has been suggested by Steele et al. (2011). However, the changes in SLC9A3 expression due to BP could be explained by an improved mechanism of expelling protons back into the ruminal lumen to maintain epithelial homeostasis. Intraepithelial $\mathrm{pH}$ homeostasis can be driven by greater VFA transport, but BP diets did not demonstrate greater VFA, except for propionate, in comparison to $\mathrm{TH}$ diets.

Monocarboxylate transporter isoform 4 tended to be affected by fiber source, with increased relative expression on TH diets $(P=0.06$; Table 6$)$. Monocarboxylate transporter isoform 1 also tended to be affected by fiber source, with increased relative expression on BP diets $(P=0.09$; Table 5$)$. Monocarboxylate transporter isoform 1 and 4 are responsible for specifically lactate, BHB (Halestrap and Meredith, 2004), and VFA (Aluwong et al., 2010) transport across the rumen epithelium and maintenance of epithelium ion homeostasis.

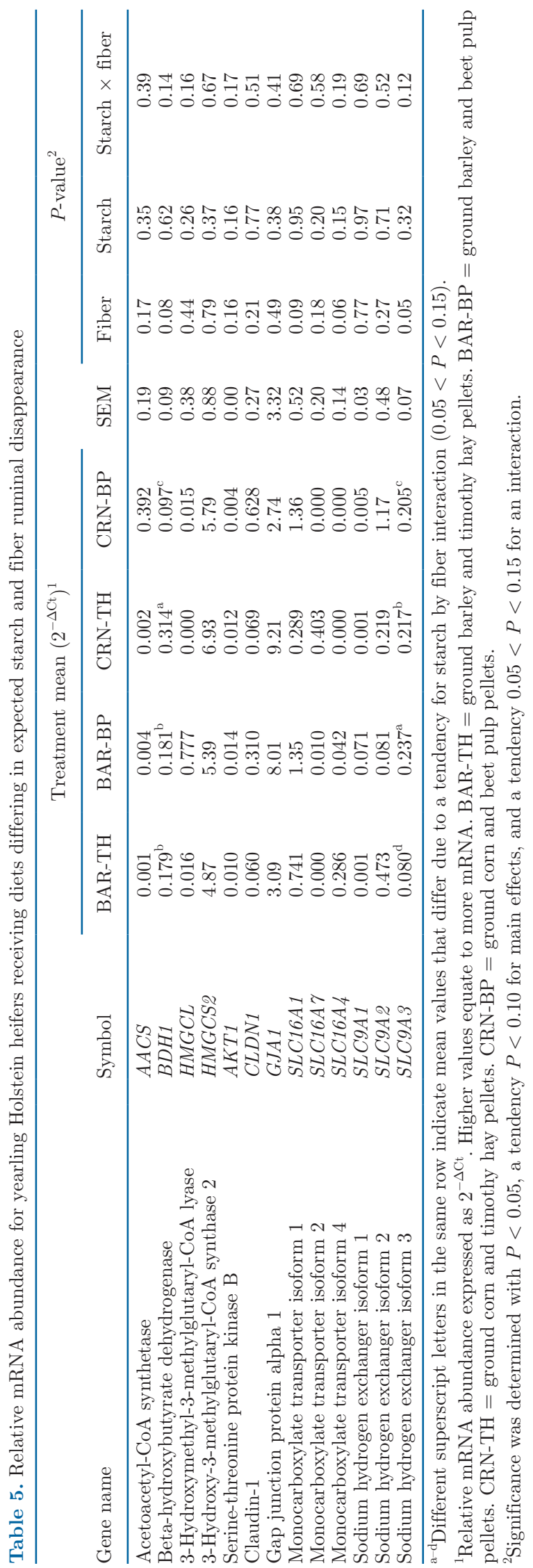


Table 6. Blood plasma metabolite concentrations for yearling Holstein heifers receiving diets differing in expected starch and fiber ruminal disappearance

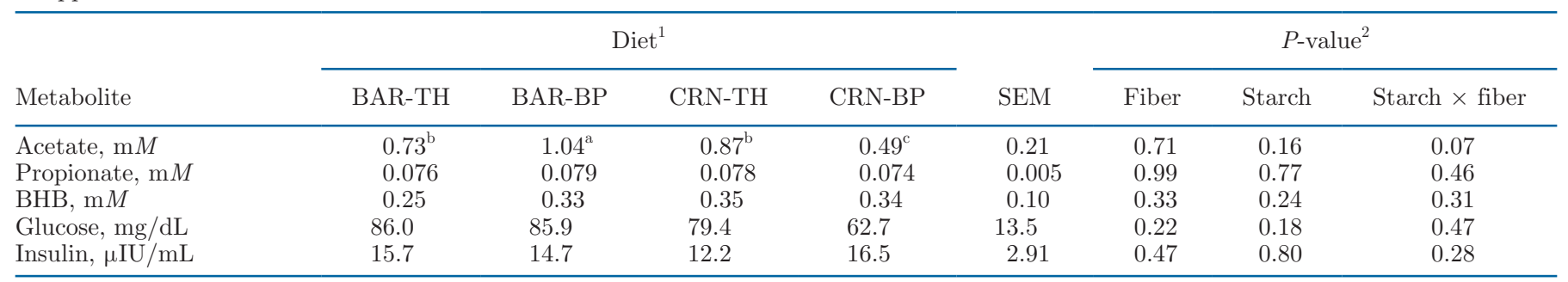

$\overline{{ }^{a-c} \text { Different superscript letters in the same row indicate mean values that differ due to a tendency for a starch by fiber interaction }(0.05<P<}$ $0.15)$.

${ }^{1} \mathrm{BAR}-\mathrm{TH}=$ ground barley and timothy hay pellets. BAR-BP $=$ ground barley and beet pulp pellets. CRN-TH = ground corn and timothy hay pellets. $\mathrm{CRN}-\mathrm{BP}=$ ground corn and beet pulp pellets.

${ }^{2}$ Significance was determined with $P<0.05$, a tendency $P<0.10$ for main effects, and a tendency $0.05<P<0.15$ for an interaction.

It was expected that the apical-most transporters [MCT4 (monocarboxylate transporter isoform 4) and NHE3 (sodium hydrogen exchanger isoform 3)] would be affected by diet because they would have the greatest and most prolonged contact with rumen fluid, but apical uptake is also the rate-limiting step. However, it was also expected that $S L C 9 A 1$ in conjunction with $S L C 16 A 1$ would be affected by treatment because the 2 types of transporters tend to work in tandem with different isoforms (Graham et al., 2007). The lack of change in $S L C 9 A 1$ does support the theory that strata position of the transporter is a driving force in regulation of expression.

It is recognized that the gene expression data may appear to diverge from the balanced approach taken with the rumen fluid collection and subsequent analysis. It is also recognized that mRNA does not equate to changes in protein expression, which would be more indicative of transporter expression and activity due to changes in VFA. Multiple other factors can influence overall epithelial gene expression such as number of cells per papilla and potential contaminating tissue and cell types due to using whole papillae tissue. These limitations highlight the need for more research that investigates ruminal transporter expression and activity.

\section{Blood Metabolites}

Table 6 includes plasma concentrations of acetate, propionate, BHB, glucose, and insulin of the different treatments. Acetate was the only metabolite that tended to be affected by treatment (starch $\times$ fiber $P$ $=0.07$ ). It was unexpected that acetate concentrations would be changed due to treatment because we expected blood acetate to be utilized by peripheral tissues and reach some degree of homeostasis before samples were taken at the tail vein. The direction and magnitude of blood acetate differences does not map to VFA pool size data, VFA concentration data, or VFA molar proportions. This discrepancy is expected due to hepatic and peripheral tissue metabolism of acetate occurring before sample collection. Future work is needed to more thoroughly understand the relationships between postabsorptive VFA supply and blood VFA dynamics.

Plasma propionate, BHB, glucose, and insulin concentrations were unaffected by starch or fiber source $(P>0.15)$. It was expected that blood propionate concentrations would not change because propionate is most likely metabolized by the liver before sample collection. Previous work measuring blood propionate concentrations during a jugular propionate infusion also found that shifts in propionate concentration were not sustained, indicating homeostatic mechanisms were maintaining blood propionate concentration (Bedford et al., 2018). Similarly to ruminal VFA concentrations, blood VFA concentrations only provide a snapshot of biological responses (Hall et al., 2015). Therefore, additional flux-based work is needed to understand blood VFA metabolism more completely.

\section{Summary of Responses to Diet Changes}

The TH diets demonstrated increased rumen $\mathrm{pH}$, acetate and isovalerate molar proportions, total VFA concentrations, VFA fluid-mediated flux from the rumen, and tended to increase relative expression of BDH1 and SLC16A4. The BP diets significantly decreased rumen $\mathrm{pH}$, tended to increase propionate molar proportions, had the significantly lowest fluid passage rate and fluid-mediated flux for all VFA, and increased the expression of SLC9A3 relative to $\mathrm{TH}$ diets. Corn diets demonstrated significant increases in valerate and propionate, but a significant decrease in butyrate molar proportions. These results suggest that higher rumen degradable NDF diets (BP diets) may not foster a rumen environment to support optimal VFA retention 
in the rumen and minimize VFA interaction with the epithelium.

\section{CONCLUSIONS}

This study demonstrated that dietary starch and fiber sources, but primarily fiber sources, generated more measurable shifts in fermentation and contribute to shifts in VFA dynamics and epithelial responses. We acknowledge that the starch source data differs from previously reported data from other studies, and additional work on starch sources differing in extent of disappearance is needed to understand whether this relative importance is simply reflecting the extent of ruminal disappearance versus rate of disappearance. The work also provides further evidence for the need for more systemic evaluation of how diets influence the fermentation environment of the rumen, including the epithelium.

\section{ACKNOWLEDGMENTS}

Research was supported by state and federal funds appropriated to Virginia Tech, and by USDA-NIFA project numbers 2015-03656 and 2017-05943. The authors declare no conflicts of interest.

\section{REFERENCES}

Allen, M. S. 2000. Effects of diet on short-term regulation of feed intake by lactating dairy cattle. J. Dairy Sci. 83:1598-1624. https:// doi.org/10.3168/jds.S0022-0302(00)75030-2.

Allen, M. S., B. J. Bradford, and M. Oba. 2009. Board Invited Review: The hepatic oxidation theory of the control of feed intake and its application to ruminants. J. Anim. Sci. 87:3317-3334. https://doi .org/10.2527/jas.2009-1779.

Allison, M. J., and M. P. Bryant. 1963. Biosynthesis of branched-chain amino acids from branched-chain fatty acids by rumen bacteria. Arch. Biochem. Biophys. 101:269-277. https://doi.org/10.1016/ S0003-9861(63)80012-0.

Allison, M. J., M. P. Bryant, I. Katz, and M. Keeney. 1962. Metabolic function of branched-chain volatile fatty acids, growth factors for ruminococci. II. Biosynthesis of higher branched-chain fatty acids and aldehydes. J. Bacteriol. 83:1084-1093. https://doi.org/10 .1128/JB.83.5.1084-1093.1962.

Aluwong, T., P. I. Kobo, and A. Abdullahi. 2010. Volatile fatty acids production in ruminants and the role of monocarboxylate transporters: A review. Afr. J. Biotechnol. 9:6229-6232.

Bedford, A., L. Beckett, K. Hardin, N. W. Dias, T. Davis, V. R. G. Mercadante, A. D. Ealy, and R. R. White. 2018. Propionate affects insulin signaling and progesterone profiles in dairy heifers. Sci. Rep. 8:17629. https://doi.org/10.1038/s41598-018-35977-1.

Bergman, E. N. 1990. Energy contributions of volatile fatty acids from the gastrointestinal tract in various species. Physiol. Rev. 70:567590. https://doi.org/10.1152/physrev.1990.70.2.567.

Chibisa, G. E., P. Gorka, G. B. Penner, R. Berthiaume, and T. Mutsvangwa. 2015. Effects of partial replacement of dietary starch from barley or corn with lactose on ruminal function, short-chain fatty acid absorption, nitrogen utilization, and production performance of dairy cows. J. Dairy Sci. 98:2627-2640. https://doi.org/ 10.3168/jds.2014-8827.
Connor, E. E., R. W. Li, R. L. Baldwin, and C. Li. 2010. Gene expression in the digestive tissues of ruminants and their relationships with feeding and digestive processes. Animal 4:993-1007. https:// doi.org/10.1017/S1751731109991285.

Deckardt, K., A. Khol-Parisini, and Q. Zebeli. 2013. Peculiarities of enhancing resistant starch in ruminants using chemical methods: Opportunities and challenges. Nutrients 5:1970-1988. https://doi .org/10.3390/nu5061970.

DePeters, E. J., J. G. Fadel, and A. Arosemena. 1997. Digestion kinetics of neutral detergent fiber and chemical composition within some selected by-product feedstuffs. Anim. Feed Sci. Technol. 67:127-140. https://doi.org/10.1016/0377-8401(96)01145-5.

Dijkstra, J., H. Boer, J. Van Bruchem, M. Bruining, and S. Tamminga. 1993. Absorption of volatile fatty acids from the rumen of lactating dairy cows as influenced by volatile fatty acid concentration, pH and rumen liquid volume. Br. J. Nutr. 69:385-396. https://doi .org/10.1079/BJN19930041.

El-Shazly, K. 1952. Degradation of protein in the rumen of sheep. 2 The action of rumen micro-organisms on amino-acids. Biochem. J. 51:647-653. https://doi.org/10.1042/bj0510647.

Fadel, J. G., E. J. DePeters, and A. Arosemena. 2000. Composition and digestibility of beet pulp with and without molasses and dried using three methods. Anim. Feed Sci. Technol. 85:121-129. https: //doi.org/10.1016/S0377-8401(00)00136-X.

Ferreira, G., Y. Yang, C. L. Teets, W. S. Brooks, and C. A. Griffey. 2018. Technical note: In situ ruminal starch disappearance kinetics of hull-less barley, hulled barley, and corn grains. J. Dairy Sci. 101:6150-6154. https://doi.org/10.3168/jds.2018-14512.

Firkins, J. L. 1997. Effects of feeding nonforage fiber sources on site of fiber digestion. J. Dairy Sci. 80:1426-1437. https://doi.org/10 .3168/jds.S0022-0302(97)76072-7.

Firkins, J. L., W. P. Weiss, M. L. Eastridge, and B. L. Hull. 1990. Effects of feeding fungal culture extract and animal-vegetable fat on degradation of hemicellulose and on ruminal bacterial growth in heifers. J. Dairy Sci. 73:1812-1822. https://doi.org/10.3168/jds .S0022-0302(90)78861-3.

France, J., and J. Dijkstra. 2005. Volatile fatty acid production. Pages 157-175 in Quantitative Aspects of Ruminant Digestion and Metabolism. 2nd ed. J. Dijkstra, J. Forbes, and J. France, ed. CABI.

Graham, C., I. Gatherar, I. Haslam, M. Glanville, and N. L. Simmons. 2007. Expression and localization of monocarboxylate transporters and sodium/proton exchangers in bovine rumen epithelium. Am. J. Physiol. Regul. Integr. Comp. Physiol. 292:R997-R1007. https: //doi.org/10.1152/ajpregu.00343.2006.

Halestrap, A. P., and D. Meredith. 2004. The SLC16 gene familyfrom monocarboxylate transporters (MCTs) to aromatic amino acid transporters and beyond. Pflugers Arch. 447:619-628. https:/ /doi.org/10.1007/s00424-003-1067-2.

Hall, M. B. 2009. Determination of starch, including maltooligosaccharides, in animal feeds: Comparison of methods and a method recommended for AOAC collaborative study. J. AOAC Int. 92:42-49. https://doi.org/10.1093/jaoac/92.1.42.

Hall, M. B., T. D. Nennich, P. H. Doane, and G. E. Brink. 2015. Total volatile fatty acid concentrations are unreliable estimators of treatment effects on ruminal fermentation in vivo. J. Dairy Sci. 98:3988-3999. https://doi.org/10.3168/jds.2014-8854.

Krämer, M., P. Lund, and M. R. Weisbjerg. 2013. Rumen passage kinetics of forage- and concentrate-derived fiber in dairy cows. J. Dairy Sci. 96:3163-3176. https://doi.org/10.3168/jds.2012-6146.

Kristensen, N. B. 2000. Quantification of whole blood short-chain fatty acids by gas chromatographic determination of plasma 2-chloroethyl derivatives and correction for dilution space in erythrocytes. Acta Agric. Scand. A Anim. Sci. 50:231-236. https://doi.org/10 .1080/090647000750069421.

Kung, L. Jr., M. C. Windle, and N. Walker. 2014. The effect of an exogenous protease on the fermentation and nutritive value of high-moisture corn. J. Dairy Sci. 97:1707-1712. https://doi.org/ 10.3168/jds.2013-7469.

Kuoppala, K., S. Ahvenjärvi, M. Rinne, and A. Vanhatalo. 2009. Effects of feeding grass or red clover silage cut at two maturity stages in dairy cows. 2. Dry matter intake and cell wall digestion kinet- 
ics. J. Dairy Sci. 92:5634-5644. https://doi.org/10.3168/jds.2009 -2250 .

Little, W., and S. R. Shaw. 1978. A note on the individuality of the intake of drinking water by dairy cows. Anim. Sci. 26:225-227. https://doi.org/10.1017/S0003356100039659.

Lu, Y., J. S. Bradley, S. R. McCoski, J. M. Gonzalez, A. D. Ealy, and S. E. Johnson. 2017. Reduced skeletal muscle fiber size following caloric restriction is associated with calpain-mediated proteolysis and attenuation of IGF-1 signaling. Am. J. Physiol. Regul. Integr. Comp. Physiol. 312:R806-R815. https://doi.org/10.1152/ajpregu .00400 .2016 .

Naderi, N., G. R. Ghorbani, A. Sadeghi-Sefidmazgi, S. M. Nasrollahi, and K. A. Beauchemin. 2016. Shredded beet pulp substituted for corn silage in diets fed to dairy cows under ambient heat stress: Feed intake, total-tract digestibility, plasma metabolites, and milk production. J. Dairy Sci. 99:8847-8857. https://doi.org/10.3168/ jds.2016-11029.

Nikkhah, A. 2012. Barley grain for ruminants: A global treasure or tragedy. J. Anim. Sci. Biotechnol. 3:22. https://doi.org/10.1186/ 2049-1891-3-22.

NRC (National Research Council). 2001. Nutrient Requirements of Dairy Cattle. 7th ed. National Academy.

Owens, F. N., and C. F. Hanson. 1992. External and internal markers for appraising site and extent of digestion in ruminants. J. Dairy Sci. 75:2605-2617. https://doi.org/10.3168/jds.S0022 -0302(92)78023-0.

Roman-Garcia, Y., R. R. White, and J. L. Firkins. 2016. Meta-analysis of postruminal microbial nitrogen flows in dairy cattle. I. Derivation of equations. J. Dairy Sci. 99:7918-7931. https://doi.org/10 $.3168 /$ jds.2015-10661.

Rozen, S., and H. Skaletsky. 2000. Primer3 on the WWW for general users and for biologist programmers. Methods Mol. Biol. 132:365386.

Rupp, G. P., K. K. Kreikemeier, L. J. Perino, and G. S. Ross. 1994. Measurement of volatile fatty acid disappearance and fluid flux across the abomasum of cattle, using an improved omasal cannulation technique. Am. J. Vet. Res. 55:522-529.

Smith, R. H. 1959. The development and function of the rumen in milk-fed calves. J. Agric. Sci. 52:72-78. https://doi.org/10.1017/ S0021859600035693.
Steele, M. A., J. Croom, M. Kahler, O. AlZahal, S. E. Hook, K. Plaizier, and B. W. McBride. 2011. Bovine rumen epithelium undergoes rapid structural adaptations during grain-induced subacute ruminal acidosis. Am. J. Physiol. Regul. Integr. Comp. Physiol 300:R1515-R1523. https://doi.org/10.1152/ajpregu.00120.2010.

Sutton, J. D., M. S. Dhanoa, S. V. Morant, J. France, D. J. Napper, and E. Schuller. 2003. Rates of production of acetate, propionate, and butyrate in the rumen of lactating dairy cows given normal and low-roughage diets. J. Dairy Sci. 86:3620-3633.

Van Soest, P. J., J. B. Robertson, and B. A. Lewis. 1991. Methods for dietary fiber, neutral detergent fiber, and nonstarch polysaccharides in relation to animal nutrition. J. Dairy Sci. 74:3583-3597. https://doi.org/10.3168/jds.S0022-0302(91)78551-2.

Varga, G. A., and W. H. Hoover. 1983. Rate and extent of neutral detergent fiber degradation of feedstuffs in situ1. J. Dairy Sci. 66:2109-2115. https://doi.org/10.3168/jds.S0022-0302(83)82057 -8 .

White, R. R., M. B. Hall, J. L. Firkins, and P. J. Kononoff. 2017a. Physically adjusted neutral detergent fiber system for lactating dairy cow rations. I: Deriving equations that identify factors that influence effectiveness of fiber. J. Dairy Sci. 100:9551-9568. https: //doi.org/10.3168/jds.2017-12765.

White, R. R., M. B. Hall, J. L. Firkins, and P. J. Kononoff. 2017b. Physically adjusted neutral detergent fiber system for lactating dairy cow rations. II: Development of feeding recommendations. J. Dairy Sci. 100:9569-9584. https://doi.org/10.3168/jds.2017-12766.

\section{ORCIDS}

L. Beckett (ㄴ) https://orcid.org/0000-0003-0176-9500

C. B. Gleason (1) https://orcid.org/0000-0001-8932-3364

A. Bedford ๑ https://orcid.org/0000-0002-1339-9466

D. Liebe (๑) https://orcid.org/0000-0003-4447-4120

T. T. Yohe $\odot$ https://orcid.org/0000-0001-7029-8322

M. B. Hall ๑ https://orcid.org/0000-0002-5460-3208

K. M. Daniels ๑ https://orcid.org/0000-0002-1437-1457

R. R. White () https://orcid.org/0000-0001-5713-012X 